\title{
FITUR LENGTH OF EDGE DAN MOMENT INVARIAN UNTUK GESTURE RECOGNITION DENGAN MENGGUNAKAN KINECT UNTUK KONTROL LAMPU
}

\author{
Rekyan Regasari MP, ST., MT. ${ }^{1}$, Budi Darma Setiawan, S.Kom., M.Cs. ${ }^{2}$, Issa Arwani, S.Kom., M.Sc. ${ }^{3}$ \\ ${ }^{1,2,3}$ Program Teknologi Informasi dan Ilmu Komputer \\ Universitas Brawijaya \\ Email: ${ }^{1}$ rekyan.rmp@ub.ac.id, ${ }^{2}$ s.budidarma@ub.ac.id, ${ }^{3}$ issa.arwani@ub.ac.id
}

(Naskah masuk: 29 Januari 2015, diterima untuk diterbitkan: 17 Februari 2015)

\begin{abstract}
Abstrak
Teknologi Kinect adalah teknologi yang dikembangkan untuk game. Kinect memungkinkan pemain game mengontrol permainan dengan menggunakan gerakan dan suara. Hal ini dikarenakan di dalam Kinect terdapat 3 hardware yang bekerja bersama-sama. Tiga hardware tersebut yaitu color VGA video camera, sensor kedalaman, dan multi array microphones. Karena itu, penelitian ini mencoba mengembangkan sensor Kinect untuk keperluan mendeteksi telapak tangan dan gesturnya untuk digunakan sebagai kontrol lampu. Hal ini dilakukan dengan menambahkan beberapa proses pengolahan citra. Pengenalan telapak tangan, menggunakan sensor VGA camera dan depth camera dalam Kinect. Ketika seorang pengguna menjulurkan tangannya kearah sensor, kemudian mengangkat jarinya maka program akan bereaksi. Jika 2 jari yang diangkat maka program akan mengaktifkan saklar padam. Sedangkan jika 5 jari yang diangkat, maka program akan mengaktifkan saklar hidup. Dalam penelitian ini ada 2 fitur yang digunakan dan dibandingkan hasilnya. Fitur yang digunakan adalah fitur Moment Invariant dan Length of Edge. Hasil lebih baik diberikan jika pengenalan dilakukan dengan menggunakan Length of Edge. Dari seluruh data uji yang dipakai, untuk pengenalan dengan menggunakan fitur Length of Edge, akurasi maksimal diperoleh sebesar $100 \%$, sedangkan dengan menggunakan fitur Moment Invariant, akurasi maksimal diperoleh sebesar $80 \%$.
\end{abstract}

Kata kunci: Moment Invarian, Length of Edge, gesture telapak tangan

\begin{abstract}
Kinect is a technology developed for game. Kinect allows players to control game play by using movement and sound. This is because Kinect has 3 hardware that work together. The three hardware are VGA video camera, depth sensor and multi-array microphones. Therefore, this study attempts to use Kinect sensor for detecting the palm's gestures and use them as a light control. This is done by adding some image processing technique. The palm's gesture detection is done by using the VGA camera and depth camera in Kinect Sensor. When a user sticking his hand out and raise his fingers, then program will gives response. If 2 fingers are raised, program will activate off switch, while if 5 fingers are raised, program will activate on switch. There are two features are used in this study, and the results are compared. The features are Moment Invariant and Length of Edge. Better results given by recognition using the Length of Edge. From all the test data used, recognition using Length of Edge give $100 \%$ accuracy, while recognition using Moment Invariant features, give $80 \%$ in acuracy.
\end{abstract}

Keywords: Moment Invarian, Length of Edge, palm gesture

\section{PENDAHULUAN}

Kinect adalah perangkat yang dicipatakan untuk keperluan game (permainan). Kinect dapat mendeteksi gerakan pada tubuh manusia untuk mengontrol permainan. Meskipun demikian, karena kemampuannya untuk mengenali gerakan tubuh itu, Kinect bisa digunakan untuk mengontrol perangkat keras lainnya. Kemampuan yang dimiliki Kinect dikarenakan terdapat 3 inovasi hardware yang bekerja bersama-sama di dalam sensor Kinect. Sensor-sensir tersebut adalah color VGA video camera, sensor kedalaman, dan multi array microphones.
Beberapa penelitian yang menggunakan teknologi Kinect ini adalah penelitian oleh 'Irfan, 2013, yang menggunakan Kinect untuk memandu robot humanoid yang telah dirancang. Sementara itu Achmad Teguh Wibowo dkk pada tahun 2013, meneliti jarak terbaik untuk menggunakan Kinect. Kinect dapat mengenali gerakan tubuh dengan baik dengan jarak minimal antara Kinect dengan tubuh adalah $\pm 0.84 \mathrm{~m}$ dan jarak maksimalnya adalah \pm 3.83 m. Di penelitiannya, Ia mengunakan Kinect untuk menyalakan LED pada port yang diinginkan dengan menggunakan gerakan tubuh.

Penelitian serupa yang sudah pernah dilakukan juga, yaitu penelitian menggunakan Kinect untuk mendeteksi gerakan telapak tangan sebagai saklar 
lampu. (Regasari, 2015). Dalam penelitian tersebut, citra telapak tangan yang diambil dengan Kinect de ekstrak fiturnya dan kemudian dilakukan klasifikasi. Fitur yang digunakan adalah Moment Invarian. Hasil yang diperoleh dari penelitian tersebut adalah akurasi sebesar $80 \%$.

Penelitian ini berusaha mengembangkan pengenalan telapak tangan yang sudah pernah dilakukan sebelumnya. Jika pada penelitian Regasari, 2015 menggunakan fitur Moment Invarian, pada penelitian kali ini akan dibandingkan hasilnya jika menggunakan fitur Length of Edge.

Ujicoba dilakukan dengan menggunakan prototype berupa software berbasis windows untuk mensimulasikan lampu padam dan menyala. Windows menyediakan SDK untuk membuat kode program yang terkoneksi dengan Kinect. Panduan membuat program berbasis windows untuk Kinect bisa dilihat pada (Catuhe, 2012).

Masalah yang dirumuskan dalam penelitian ini adalah: (1) Bagaimana mendeteksi gestrur telapak tangan dengan menggunakan sensor Kinect. (2) Bagaimana hasil akurasi deteksi gesture dengan Kinect, ketika menggunakan fitur Moment Invariant dan Length of Edge.

\section{KINECT}

Kinect adalah perangkata yang dibuat oleh Microsoft untuk merubah cara bermain seseorang di dalam permainan yang biasanya hanya menggunakan joystick, sekarang dapat berinteraksi dengan permainan dengan menggunakan gerakan badan (Zeng, 2012). Kinect mampu meningkatkan interkasi dengan pemain karena memiliki 3 sensor, yaitu: depth sensor, color camera, dan, four-microphone array. (Zeng, 2012). Bentuk Kinect dapat dilihat dalam Gambar 1.
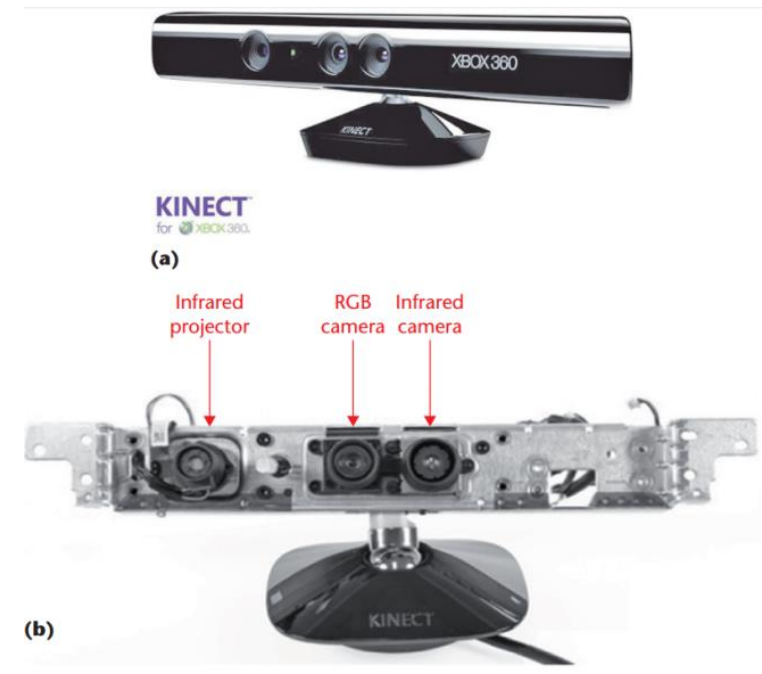

Gambar 1. Kinect untuk Xbox. (a) Kinect untuk Xbox 360. (b)beberapa sensor dalam Kinect sumber: Zeng, 2012

\section{MOMENT INVARIAN}

Momen Invarian dikenalkan oleh Hu pada tahun 1962 yang merupakan fungsi nonlinear yang invarian terhadap rotasi, translasi dan skala. (Gonzales, R.and R. E. Wood. 2002)

Momen dapat menggambarkan area suatu objek, posisi, orientasi dan parameter terdefinisi lainnya. Persamaan dasar dari momen suatu objek didefinisikan sebagai seperti di persamaan (1).

$$
m_{i j}=\sum_{x} \sum_{y} x^{i} y^{j} a_{x y}
$$

(Flusser, Jan and Tomas Suk, 2009). Parameter $(i+j)$ adalah order dari moment, $\mathrm{x}$ dan $\mathrm{y}$ menyatakan koordinat titik pixel, sedangkan $\mathrm{a}_{\mathrm{xy}}$ menyatakan intensitas titik pada koordinat $(\mathrm{x}, \mathrm{y})$.

Momen tingkat ke-0 (zero order moment dilambangkan dengan $\mathrm{m}_{00}$ ) dan ke-1 (first-order moments dilambangkan dengan $\mathrm{m}_{01}$ dan $\mathrm{m}_{10}$ ) didefinisikan sebagai persamaan (2), (3), dan (4).

$$
\begin{aligned}
& m_{00}=\sum_{x} \sum_{y} a_{x y} \\
& m_{10}=\sum_{x} \sum_{y} x . a_{x y} \\
& m_{01}=\sum_{x} \sum_{y} y \cdot a_{x y}
\end{aligned}
$$

(Flusser, Jan and Tomas Suk, 2009)

Pada citra biner, $\mathrm{a}_{\mathrm{xy}}$ akan bernilai 0 atau 1. Jika objek dari suatu citra bernilai 1, dan latar blakangnya bernilai 0 , maka moment tingkat ke-0 ( $\left.\mathrm{m}_{00}\right)$ menggambarkan area dari objek.

Untuk mencari titik pusat dari area atau masa (centroid) digunakan persamaan (5).

$$
x^{\prime}=\frac{m_{10}}{m_{00}} \text { dan } y^{\prime}=\frac{m_{01}}{m_{00}}
$$

(Flusser, Jan and Tomas Suk, 2009)

dengan (x',y') merupakan pusat koordinat dari objek.

Momen pusat (central moment) $\mu$ adalah momen yang bersesuaian dengan pusat area, didefinisikan pada persamaan (6).

$$
\mu_{i j}=\sum_{x} \sum_{y}\left(x-x^{\prime}\right)^{i}\left(y-y^{\prime}\right)^{j} a_{x y}
$$

(Flusser, Jan and Tomas Suk, 2009)

dan momen pusat yang ternormalisasi dinyatakan dengan persamaan (7).

$$
\eta_{i j}=\frac{\mu_{i j}}{\left(\mu_{00}\right)^{\lambda}}
$$

(Flusser, Jan and Tomas Suk, 2009)

$$
\begin{aligned}
& \qquad \lambda=\frac{(i+j)}{2}+1, \quad \text { dan }(i+j) \geq 2 \text { (momen } \\
& \text { dengan } \\
& \text { tingkat ke-1 adalah selalu invarian). }
\end{aligned}
$$


Dari momen ternormalisasi pada persamaan (7), sekumpulan momen-momen Invarian (invariant moments) dapat didefinisikan. Momen-momen ini sangat berguna dalam membuat vektor ciri untuk pengenalan objek. Ada 7 buah nilai momen yang dijabarkan dari persamaan (8) hingga (14).

$$
\begin{aligned}
& \phi_{1}=\eta_{20}+\eta_{02} \\
& \phi_{2}=\left(\eta_{20}+\eta_{02}\right)^{2}+4 \eta_{11}^{2} \\
& \phi_{3}=\left(\eta_{30}-3 \eta_{12}\right)^{2}+\left(3 \eta_{21}-\eta_{03}\right)^{2} \\
& \phi_{4}=\left(\eta_{30}+\eta_{12}\right)^{2}+\left(\eta_{21}+\eta_{03}\right)^{2} \\
& \phi_{5}=\left(\eta_{30}-3 \eta_{12}\right)\left(\eta_{30}+\eta_{12}\right) \\
& \left\{\left(\eta_{30}+\eta_{12}\right)^{2}-3\left(\eta_{21}+\eta_{03}\right)^{2}\right\}+ \\
& \left(3 \eta_{21}-\eta_{03}\right)\left(\eta_{21}+\eta_{03}\right) \\
& \left\{3\left(\eta_{30}+\eta_{12}\right)^{2}-\left(\eta_{21}+\eta_{03}\right)^{2}\right\} \\
& \phi_{6}=\left(\eta_{20}-\eta_{02}\right)\left\{\left(\eta_{30}+\eta_{12}\right)^{2}-\left(\eta_{21}+\eta_{03}\right)^{2}\right\}+ \\
& 4 \eta_{11}\left(\eta_{30}+\eta_{12}\right)\left(\eta_{21}+\eta_{03}\right) \\
& \phi_{7}=\left(3 \eta_{21}-\eta_{30}\right)\left(\eta_{30}+\eta_{12}\right) \\
& \left\{\left(\eta_{30}+\eta_{12}\right)^{2}-3\left(\eta_{21}+\eta_{03}\right)^{2}\right\}+ \\
& \left(3 \eta_{21}-\eta_{03}\right)\left(\eta_{21}+\eta_{03}\right) \\
& \left\{3\left(\eta_{30}+\eta_{12}\right)^{2}-\left(\eta_{21}+\eta_{03}\right)^{2}\right\}
\end{aligned}
$$

(Flusser, Jan and Tomas Suk, 2009)

Tujuh nilai Moment Invarian tersebut adalah invarian terhadap transformasi citra termasuk di dalamnya skala, translasi dan rotasi. Bagaimanapun juga tujuh Momen Invarian ini tidak invarian terhadap perubahan kontras.

\section{LENGTH OF EDGE}

Pada penelitian ini, diperkenalkan fitur Length of Edge, yaitu fitur yang menggambarkan panjang tepian dari sebuah objek pada citra. Satuannya adalah pixel. Fitur ini didapatkan dengan cara menghitung banyaknya pixel yang merupakan tepian objek, atau keliling dari sebuah objek. Penjelasannya bisa dilihat seperti dalam Gambar 2.

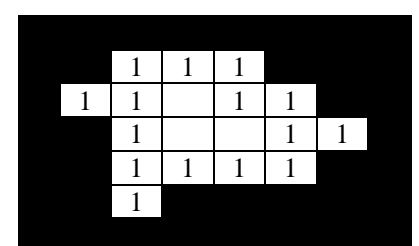

Gambar 2. Fitur Length of Edge
Pada Gambar 2, angka 1 menunjukkan tepian dari objek. pada gambar tersebut, fitur Length of Edge-nya sebesar 15.

Fitur ini dipilih sebab gestur tangan yang digunakan melibatkan jari. Panjang tepian objek tangan dengan 5 jari terbuka akan memiliki panjang tepian yang lebih panjang jika dibandingkan dengan objek tangan yang digenggam. Tentunya ukuran tangan yang digunakan harus sama, untuk itu perlu dilakukan penyekalaan objek tangan ke dalam ukuran yang seragam.

\section{METODE PENELITIAN}

Metode untuk mendeteksi telapak tangan, menggunakan metode yang sama dalam penelitian Regasari tahun 2015, yaitu menggunakan sensor depth camera dan RGB camera pada Kinect. Depth camera dapat mendeteksi tingkat kedalaman (jarak relatif) objek-objek yang ditangkap dalam sensor ini. Sedangkan rgb camera adalah kamera biasa, yang menangkap gambar dan menterjemahkannya ke dalam warna dasar yaitu: merah, hijau dan biru.

Dari kedua sensor tersebut akan diambil citra telapak tangan. Citra telapak tangan akan bisa terdeteksi pada program, jika pengguna menjulurkan tangannya kearah sensor. Warna kulit dideteksi dengan menggunakan $R G B$ camera. Dan agar yang terambil hanya telapak tangan saja, maka pengguna diharuskan menjulurkan telapak tangannya ke arah sensor, dan dideteksi dengan menggunakan depth camera. Prinsip kerjanya adalah, sensor akan menagkap warna kulit yang terdekat. Jika pengguna menjulurkan telapak tangannya, maka hanya tepak tangannya yang terlihat, wajah dan lengannya tidak akan terlihat, sebab posisinya lebih jauh dari telapak tangan.

Setelah bentuk telapak tangan didapat, citra tersebut dipotong (crop) dan diubah ukurannya (resize) sehingga objek tangan akan memenuhi citra. Ketentuannya adalah:

1. Ukuran pixel dari citra yang digunakan harus tetap. Dalam penelitian ini, ukurannya diubah menjadi 285 x 285 pixel.

2. Gambar tangan harus memenuhi citra (stretch). Artinya ujung atas tangan berada di ujung atas citra, ujung bawah tangan berada di ujung bawah citra, dan begitu juga dengan ujung kiri dan kanannya.

Langkah selanjutnya adalah mengekstraksi fitur Moment Invarian dan lengt of edge.

Penelitian ini menggunakan dua macam gestur. Gesture tersebut bisa dilihat pada gambar 3 . Dari citra telapak tangan yang diperoleh, kemudian diolah, untuk mendapatkan fitur. Fitur-fitur yang diperoleh digunakan untuk pengenalan bentuk. Dalam penelitian ini, fitur yang digunakan adalah moment inverian, dan Length of Edge (panjang tepian objek). 
(a)

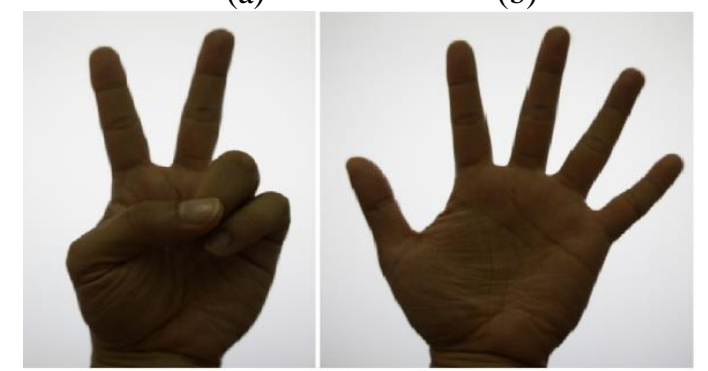

Gambar 3. Gambar gesture tangan yang digunakan dalam penelitian;

(a) gesture menyala; (b) gesture padam

Pada tahap perancangan dibuat desain pengenalan gestur, dan desain software simulasi serta desain pengujian. Rancangan sistem secara umum ditunjukkan oleh Gambar 4.

\section{AKUSISI CITRA TELAPAK TANGAN}

Pada penelitian ini, sensor Kinect yang digunakan adalah sensor Kinect for Xbox. Di dalam sensor Kinect ini terdapat beberapa sensor, dan yang dipergunakan dalam penelitian ini adalah RGB camera dan depth camera. RGB camera digunakan untuk mengambil gambar yang memiliki warna kulit. Referensi warna kulit yang digunakan, mengambil hasil penelitian oleh Lin, Chiunhsiun tahun 2005. Sedangakan depth camera digunakan untuk mengambil gambar-gambar yang merupakan warna kulit, tetapi yang paling dekat dengan posisi Kinect berada. Ini berarti, jika seseorang menjulurkan tangannya kearah Kinect, maka wajah, leher, dan lengannya tidak akan tertangkap kamera. Hal ini dikarenakan, walaupun wajah, leher, dan lengan memiliki warna yang sama dengan telapak tanga (warna kulit), tetapi letaknya jauh dibelakang telapk tangan.

\section{EKSTRAKSI FITUR}

Pada penelitian ini ada 2 fitur yang digunakan, dan diujicoba secara terpisah, yang pertama adalah fitur dengan menggunakan Moment Invariant, dan yang kedua adalah menggunakan Length of Edge atau panjang pixel dari tepian objek tangan.

\subsection{Moment Invarian}

Dalam proses mengenali gesture, setiap gesture tangan akan dicari 7 nilai momen invariannya. Tujuh nilai momen ini kemudian akan diukur jaraknya dengan nilai moment yang dimiliki oleh data latih data latih yang sudah ada. Jarak diukur dengan menggunakan rumus Euclidean distance.

Nilai data latih yang terdekat akan diadopsi sebagai hasil. Namun sebelum pengukuran jarak dilakukan. Setiap nilai moment dinormalisasi dulu dengan menggunakan nilai log absolute dari nilai aslinya. Persamaannya bisa dilihat pada persamaan (15)

$$
\text { normal }=\log (\text { abs }(\text { nilai moment }))
$$

\subsection{Length of Edge}

Pada pengukuran Length of Edge, yang diukur adalah jumlah pixel putih yang ada pada tepian tangan. Dasar pemikirannya adalah jika 5 jari terangkat, maka panjang tepiannya akan semakin panjang, jika dibandingkan dengan ketika hanya 2 jari yang terangkat. Metode ini memiliki batasan agar bisa berhasil diterapkan, antara lain:

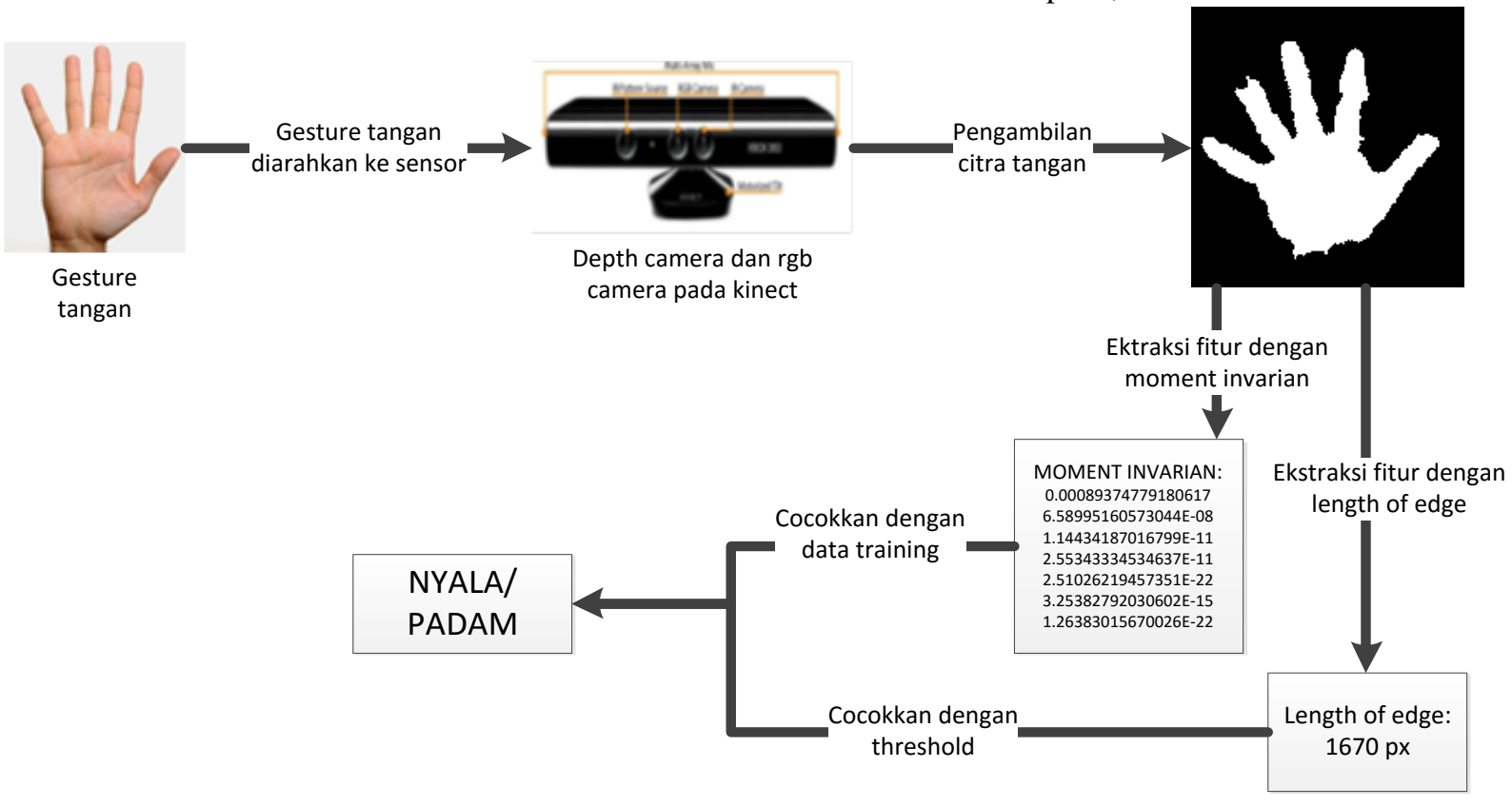

Gambar 4. Bagan alir proses penelitian 
1. Ukuran pixel dari citra yang digunakan harus tetap. Dalam penelitian ini, ukurannya diubah menjadi 285 x 285 px.

2. Gambar tangan harus memenuhi citra (stretch). Artinya ujung atas tangan berada di ujung atas citra, ujung bawah tangan berada di ujung bawah citra, dan begitu juga dengan ujung kiri dan kanannya.

Dari beberapa kali percobaan, didapatkan bahwa, untuk ukuran citra 285 x 285, jika kelima jari diangkat, panjang tepiannya akan lebih besar dari 1550 px. Maka angka inilah yang menjadi nilai threshold. Artinya, jika sebuah citra tangan diukur fitur Length of Edge-nya, kemudian didapatkan angka lebih dari 1550 px, maka artinya kelima jari terbuka.

\section{IMPLEMENTASI}

Ada dua skenario yang dilakukan dalam penelitian ini. Yang pertama adalah skenario untuk menguji tentang jenis fitur yang digunakan. Hal ini untuk mengetahui fitur mana yang menghasilkan hasil yang lebih baik, momen ivariant atau Length of Edge. Skenario yang kedua adalah dengan mencoba tangan dari orang yang berbeda. Skenario kedua ini diujikan untuk hasil yang terbaik pada skenario pertama, sehingga nanti kita bisa melihat, apakah fitur tersebut reliable terhadap perbedaan tangan.

Persentase akurasi didapat dari persamaan (16)

$$
\frac{\text { jumlah pengenalan yang benar }}{\text { jumlah total uji coba }} \times 100 \%
$$

Hasil implementasi program untuk melakukan pengujian dapat dilihat pada gambar 5 .

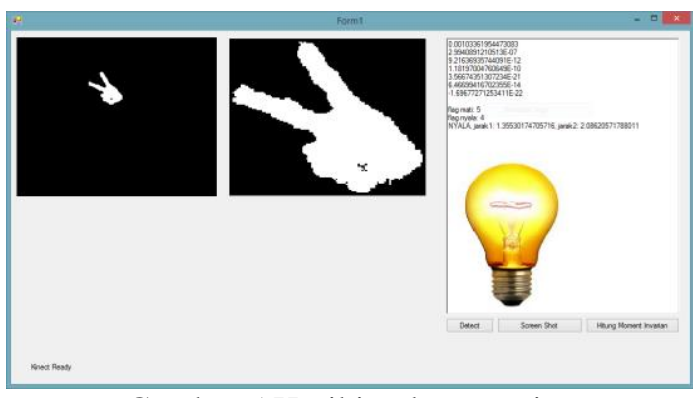

Gambar 5 Hasil implementasi

\section{HASIL DAN PEMBAHASAN}

\subsection{Pengujian dengan Moment Invarian}

Berdasarkan tabel 1, didapatkan akurasi sebesar $8 / 10 \times 100 \%=80 \%$. Dari dua percobaan yang salah, salah satunya salah deteksi (gesture no 2), dan yang satu lagi tidak dapat mengenali (gesture no 9).

Tabel 1. Hasil pengujian dengan Moment Invarian

\begin{tabular}{llcc}
\hline $\begin{array}{l}\text { Nomor } \\
\text { gesture }\end{array}$ & Hasil & $\begin{array}{c}\text { Hasil Yang } \\
\text { Diharapakan }\end{array}$ & $\begin{array}{c}\text { Kebe- } \\
\text { naran }\end{array}$ \\
\hline
\end{tabular}

\begin{tabular}{cccc}
\hline 1 & Menyala & Menyala & 1 \\
\hline 2 & Padam & Menyala & 0 \\
\hline 3 & Meyala & Menyala & 1 \\
\hline 4 & Menyala & Menyala & 1 \\
\hline 5 & Menyala & Menyala & 1 \\
\hline 6 & Padam & Padam & 1 \\
\hline 7 & Padam & Padam & 1 \\
\hline 8 & Padam & Padam & 1 \\
\hline 9 & no command & Padam & 0 \\
\hline 10 & Padam & Padam & 1 \\
\hline
\end{tabular}

\subsection{Pengujian dengan Length of Edge}

Dari tabel 2 terlihat bahwa hasil akurasinya adalah $13 / 13 \times 100 \%=100 \%$ benar. hal ini disebabkan karena memang dalam beberapa kali percobaan, semua nilai Length of Edgenya berada diatas threshold untuk gesture mati, dan berada di bawah threshold untuk gesture menyala.

Taber 2. Hasil pengujian dengan length

\begin{tabular}{ccccc}
\hline $\begin{array}{c}\text { Nomor } \\
\text { Gesture }\end{array}$ & $\begin{array}{c}\text { Length } \\
\text { of } \\
\text { Edge } \\
\text { (pixel) }\end{array}$ & Hasil & $\begin{array}{c}\text { Hasil yang } \\
\text { diharapkan }\end{array}$ & $\begin{array}{c}\text { Kebe- } \\
\text { naran }\end{array}$ \\
\hline 1 & 1679 & Mati & Mati & 1 \\
\hline 2 & 1733 & Mati & Mati & 1 \\
\hline 3 & 1599 & Mati & Mati & 1 \\
\hline 4 & 1705 & Mati & Mati & 1 \\
\hline 5 & 1756 & Mati & Mati & 1 \\
\hline 6 & 1617 & Mati & Mati & 1 \\
\hline 7 & 1211 & Menyala & Menyala & 1 \\
\hline 8 & 1262 & Menyala & Menyala & 1 \\
\hline 9 & 1260 & Menyala & Menyala & 1 \\
\hline 10 & 1173 & Menyala & Menyala & 1 \\
\hline 11 & 1500 & Menyala & Menyala & 1 \\
\hline 12 & 1203 & Menyala & Menyala & 1 \\
\hline 13 & 1131 & Menyala & Menyala & 1 \\
\hline
\end{tabular}

\subsection{Pengujian Length of Edge dengan orang yang berbeda.}

Untuk pengujian dengan orang yang berbeda, hasilnya dapat dilihat pada tabel 3 . Ternyata tabel tersebut menunjukkan hasil yang baik. Percobaan dapat menghasilkan akutrasi yang baik karena nilai Length of Edgenya juga sesuai dengan yang diharapkan. Hal ini dapat terjadi karena proses resize yang dilakukan. Dengan adanya resizing, maka ukuran telapak tangan akan selalu sama, meskipun orangnya berbeda. Namun perlu dicatat bahwa gestur yang digunakan untuk membedakan menyala dan 
padam, bentuknya berbeda jauh. Dua jari untuk menyala, dan lima jari untuk padam. Jika mengangkat 4 jari, bisa jadi hasilnya akan berbeda, sehingga perlu dilakukan pengukuran ulang terhadap threshold yang digunakan.

Tabel 1 Hasil pengujian fitur Length of Edge pada orang yang berbeda

\begin{tabular}{ccccc}
\hline $\begin{array}{c}\text { Nomor } \\
\text { Gesture }\end{array}$ & $\begin{array}{c}\text { Length } \\
\text { of } \\
\text { Edge }\end{array}$ & Hasil & $\begin{array}{c}\text { Hasil yang } \\
\text { diharapkan }\end{array}$ & $\begin{array}{c}\text { Kebe- } \\
\text { naran }\end{array}$ \\
\hline 1 & 1569 & Mati & Mati & 1 \\
\hline 2 & 1727 & Mati & Mati & 1 \\
\hline 3 & 1746 & Mati & Mati & 1 \\
\hline 4 & 1587 & Mati & Mati & 1 \\
\hline 5 & 1677 & Mati & Mati & 1 \\
\hline 6 & 1327 & Menyala & Menyala & 1 \\
\hline 7 & 1155 & Menyala & Menyala & 1 \\
\hline 8 & 1231 & Menyala & Menyala & 1 \\
\hline 9 & 1142 & Menyala & Menyala & 1 \\
\hline 10 & 1270 & Menyala & Menyala & 1 \\
\hline Keterbatan
\end{tabular}

Keterbatasan dari fitur length of edge ini adalah sangat tergantung dengan ukuran citra yang digunakan. Ukuran citra yang berubah akan menyebebkan threshold yang digunakan juga berubah. Besarnya tentu harus melalui percobaan kembali. Hal ini berbeda dengan fitur Moment Invariant yang tidak dipengaruhi (infarian) dengan ukuran.

\section{KESIMPULAN}

Dari implementasi dan percobaan yang telah dilakukan dapat disimpulkan sebagai berikut:

1) Pada penelitian ini, untuk mendapatkan gambar telapak tangan, digunakan sensor berupa RGB camera dan depth camera. Sedangakan fitur yang digunakan untuk mengenali adalah fitur momen invarian untuk percobaan pertama, dan fitur Length of Edge untuk percobaan kedua.

2) Pada percobaan dengan fitur Length of Edge, ukuran gambar harus sama, sehingga perlu dilakukan resizing. Nilai threshold optimal yang digunakan adalah sebesar 1550 pixel.

Tingkat akurasi pengenalan gestur tangan untuk menyalakan lampu tergantung dari fitur pengenalan yang digunakan. jika menggunakan fitur momen invarian, nilai akurasi maksimalnya adalah sebesar $80 \%$ dan dengan menggunakan Length of Edge tingkat akurasinya sebesar $100 \%$.

\section{DAFTAR PUSTAKA}

Catuhe, D. 2012. Programming With the Kinect For Windows Software Development Kit. Microsoft Press.

'Irfan, Shahrul, Juni 2013, “Kinect Controlled Humanoid Robot Based On Human Body Gesture.

Regasari, R., Setiawan, B.D., Arwani, I., 2015, "Moment Invariant Untuk Pengenalan Citra Telapak Tangan Dari Kinect". Konferensi Nasional Sistem Informasi 2015 (KNSI2015), Manado.

Wibowo, Achmad Teguh, dkk, Juni 2013, "Teknologi Natural User Interface Menggunakan Kinect sebagai Pemicu Kerja Perangkat Keras bebasis Fuzzy Inference System", Jurnal EECCIS vol 7 no 1.

Flusser, Jan and Tomas Suk. 2009. Moment and Moment Invarian in Pattern Recognition. Prague, Czech Republic: WILEY.

Gonzales, R.and R. E. Wood. 2002. Digital Citra Processing, Second Edition., New Jersey: Prentice Hall, Inc.

Zeng, W., 2012, Microsoft Kinect Sensor and Its Effect, IEEE MultiMedia, April-June 2012. 